\title{
As apologias da História: écfrase e exercícios poéticos na aclamação de D. João VI
}

Alfredo Cordiviola ${ }^{1}$

\section{Resumo}

Este ensaio analisa os vínculos entre episódio histórico e registro poético que se condensam na Relação dos Festejos, cartilha publicada em $1818 \mathrm{com}$ o propósito de descrever e deixar constância das cerimônias de aclamação de D. João VI como Rei do fugaz Reino Unido de Portugal, Brasil e Algarves, ocorridas nesse ano na cidade do Rio de Janeiro. Sendo o Rio a capital do recém-criado Reino, e onde a família real, diante das expansões napoleônicas, tinha se instalado com a corte dez anos antes, a cidade se transforma em cenário principal das celebrações, marcadas, no espaço urbano, pelos artefatos efêmeros, as decorações alusivas e os poemas laudatórios que homenageiam a figura do Monarca.

Palavras-chave: Poesia encomiástica; D. João VI; festividades públicas; Rio de Janeiro

\section{Abstract}

This essay analyzes the relations between historical episode and poetic record that are condensed in the Relação dos Festejos, booklet published in 1818 with the purpose of describing and putting record of the ceremonies

\footnotetext{
${ }^{1}$ Doutor pela University of Nottingham. Professor Titular do Departamento de Letras da UFPE. E-mail: alfredo.cordiviola@gmail.com.
} 
of acclamation of D. João VI as King of the short-lived United Kingdom of Portugal, of the Brazil and Algarves, celebrated in that year in the city of Rio de Janeiro. Being Rio the capital of the newly created Kingdom, where the royal family, forced by the Napoleonic expansions, had settled with the Court ten years before, the city becomes the main scene of the celebrations, which were embodied in the urban space by ephemeral artifacts, allusive decorations and laudatory poems that honored the figure of the Monarch.

Keywords: Encomiastic Poetry; D. João VI, public celebrations; Rio de Janeiro

$\mathrm{Na}$ história das expansões ultramarinas e da instauração do colonialismo europeu que se desenvolve a partir da primeira travessia atlântica de Cristovão Colombo, o translado da corte portuguesa ao Rio de Janeiro constitui certamente uma anomalia. Perante o avanço e as conquistas dastropas napoleônicas, que convulsionavam aordemmundial então vigente, o governo imperial abandona Lisboa e se radica no Brasil. A chegada de Dom João VI e dos funcionários reais em 1808, junto com a paulatina implantação no novo solo das peças necessárias para garantir o funcionamento da maquinaria burocrática governamental, transformamo Rio em centro político do Império e invertem as relações de poder entre metrópole e periferia.

Essa anomalia, legitimada a partir das primeiras medidas adotadas (tais como a abertura dos portos ao comércio exterior ou o levantamento da proibição de elaborar manufaturas, entre outras que consolidavam a inédita situação), tenderia a se aprofundar nos anos seguintes. Em 1815, e mesmo diante do ocaso já inevitável do poderio napoleônico, haveria de receber um impulso ainda maior. Nesse ano, em carta de lei datada em 16 de dezembro, o então Príncipe Regente D. João criava uma entidade tríplice, que passava a ser conhecida como o "Reino Unido de Portugal e 
doBrasile Algarves", cuja sede continuaria estando no Rio de Janeiro.Com esse nome se unificavam todos os domínios portugueses, sob a figura de três reinos autônomos governados por um único monarca. Meses depois, perante o falecimento da rainha D. Maria I, esse monarca seria D. João, que adotava o altissonante e fantasioso título de "Rei do Reino Unido de Portugal, edo Brasil, eAlgarves, d'aquém, ed'além marem Africa, Senhor de Guiné, e da Conquista, Navegação e Commercio da Ethiopia, Arabia, Persia e da India".

O novo monarca, e o recém-criado Reino Unido, precisavam de símbolos e de cerimônias que viessem a afirmar a existência dessa inventiva figura no marco geopolítico presente. Nesse sentido, imediatamente foi disposta por ordem régia a criação do brasão do novo e unido reino. Assim, regulamentando a heráldica oficial, D. João determinava:

I. Que o Reino do Brasil tenha por Armas huma Esféra Armillar de Ouro em campo azul.

II. Que o Escudo Real Portuguez, inscrito na dita Esféra Armillar de Ouro em campo azul, com huma Corôa sobreposta, fique sendo de hoje em diante as Armas do Reino Unido de Portugal, e do Brasil, e Algarves, e das mais Partes integrantes da Minha Monarquia. (METELO DE SEIXAS, p.111)

O símbolo, que posteriormente seria transfigurado nos emblemas do Brasil independente e da República Portuguesa, estaria presente na numismática, nos retratos da família real, nas obras arquitetônicas e de engenharia, nos documentos públicos e nas artes decorativas. Era o instrumento que identificava civil e militarmente o Estado e a Monarquia regente. Contudo, para que a existência do reino fosse referendada, não bastava contar com um brasão. Era necessário que houvesse uma grande celebração, que confirmasse em praça pública o estatuto de D. João VI como autoridade suprema da entidade política que havia sido fundada. Essa festa de aclamação do monarca seria realizada no Rio de Janeiro em 
fevereiro de 1818, e a seguir eternizada na Relação dos acontecimentos publicada imediatamente depois pela Tipografia Real.

O documento, que até hoje se conserva na Biblioteca Nacional, faz parte da literatura panegírica e oficiosa encarregada de registrar e de descrever o teor das celebrações. Como nas cidades do México, em Puebla ou em Lima, esses textos eram complementos indispensáveis de toda comemoração pública, e serviam para deixar constância dos episódios mais marcantes da vida colonial, tais como a chegada de novos governantes, a coroação de um novo monarca, a nomeação de autoridades eclesiásticas, as festas religiosas, o falecimento, aniversário ou o casamento de algum membro da família real. Atrelados ao calendário litúrgico e às manifestações do poder imperial, estes eventos festivos contribuíam, portanto, a reforçar a ordem estabelecida, e, em contextos marcados por constantes tensões e atritos entre as classes dominantes e as subalternas, fortaleciam, pelo menos temporariamente, os laços de coesão social que vigoravam no reino, garantindo assim a continuidade dos pactos vigentes.

Os livretos alusivos eram assim testemunhos impressos da cidade letrada, que sancionavam o acontecimento histórico como tal, para beneplácito dos presentes e conhecimento das gerações futuras. Tratava-se geralmente de opúsculos breves, patrocinados pelas autoridades locais. Suas funções consistiam em relatar pontualmente a evolução das solenidades, enunciar os ritos cumpridos e descrever os artefatos efêmeros, como os arcos triunfais ou os catafalcos imperiais, erigidos como monumentos reverenciais para ser apreciados pelas heterogêneas massas urbanas. Os folhetos incluíam também as odes, os sonetos e as loas que haviam sido pronunciadas na ocasião. No Novo Mundo, um dos primeiros desses textos fora escrito na cidade do México pelo professor e retórico Francisco Cervantes de Salazar em meados do século XVI, para acompanhar as cerimônias fúnebres que despediam in absentia o imperador Carlos I. Haveria muitos outros ao longo dos séculos XVII e XVIII. A Relação de 1818 era umexemplar 
tardio e crepuscular de um gênero que, como o antigo regime que o promovera, estava prestes a desaparecer.

Como seu título indica, a Relação dos Festejos que a felizaclamação do muito alto, muito poderoso, e fidelíssimo Senhor D. João VI, é um texto eminentemente apologético, que aspira a registrar a "memoria do plauzivel sucesso, de que mais se glorião os fastos portuguezes", enquanto multiplica laudatórios adjetivos e perífrases grandiloquentes para exaltar com afinco a figura do Rei. ${ }^{2} \mathrm{~A}$ Relação está dividida em duas grandes partes. A primeira retrata o espaço urbano, que, embelezado cuidadosamente para a ocasião, servira de palco para o regozijo popular. Menciona as iluminadas embarcações de guerra ancoradas no porto, o Paço todo ornamentado, as fachadas e janelas decoradas com coroas e lemas, que pareciam competir entre si em chamar mais a atenção das multidões congregadas nas ruas. Nesse cenário urbano seriam montados os arcos triunfais, os templos, as pirâmides, as pinturas, legendas e iluminações, elementos cenográficos que o texto, invocando as virtudes da écfrase, tenta descrever singular e detalhadamente. A segunda parte está integrada por um conjunto de poesias dedicadas ao Rei, reunidas por Bernardo Avellino Ferreira e Souza, definido na portada como "Official Supranumerario da Secretaria da Intendencia Geral da Policia". São três odes sem autor declarado, um soneto também anônimo (ou da autoria do antologista), e um canto épico escrito por Estanislau Vieira Cardozo, escriturário e soldado de milícias da corte.

Como no México ou no Peru, os artefatos triunfais eram no Rio de 1818 os grandes protagonistas dos fastos. Segundo a Relação dos Festejos informa, eram as peças centrais da mise-en-scène que, junto com as algaravias e as declamações, as iluminações e os cortejos, transfiguravam o espaço público e tomavam conta das ruas da cidade. Profusamente elaborados, encarregados pelo poder público, pelas autoridades eclesiásticas e por particulares, eram grandes peças arquitetônicas de

\footnotetext{
${ }^{2}$ Otextopode ser consultadono Acervo Digital da Biblioteca Nacional(http://objdigital. bn.br/objdigital2/acervo_digital/div_obrasgerais/drg1423562/drg1423562.pdf)
} 
caráter efêmero; com seus esplendores, volumes, pinturas, emblemas e epigramas passageiros, reinavam brevemente, já que eram desmontados e destruídos uma vez que a festa concluía.

Artefatos suntuosos e precários, estes monumentos eram, assim, frágeis instalações temporárias, de utilidade pontual. Porém, apesar da sua irremissível caducidade e das suas apressadas composições materiais, estavam dotados de uma espécie de sacralidade que perpassava sua fugaz existência. Se os arcos de mármore ou pedra da Antiguidade eram erigidos para alimentar a memória das guerras e das famas e para preservar fatos históricos com esperanças de eternidade, estas edificações fugazes serviam antes de tudo para decorar o presente, como investimento urbano destinado a impressionar os sentidos e doutrinar as percepções dos participantes da celebração.

Nestes dispositivos confluíam a arquitetura, a pintura e a poesia, os volumes e os planos, as telas, as madeiras e os bronzes, as ordens compósitas, dóricas e coríntias, a palavra e a cor, a língua latina e a língua romance, detalhes menores para ver de perto e amplas perspectivas para apreciar ao longe. Eram objetos retóricos e visuais: falavam através das suas imagens, mostravam através dos seus emblemas e versificações. Cada elemento que integrava a composição era relativamente autônomo, mas adquiria seu significado final na narrativa quando apreciado como mais uma parte do conjunto. Através das diversas articulações que postulavam as pinturas e os textos entre si, com a cena circundante e com todos os atores envolvidos, o artefato, monumental por escala real e pelas alusões que emanava, ditava as regras do espetáculo e conformava a prova mais evidente da devoção que a cidade reservava para seu soberano.

Apesar de tanta magnificência, ao apagar das luzes nada restava dessas arquiteturas panegíricas. Somente permanecem, entretanto, na memória dos livros que, como a Relação, as descreviame as reinventavam por escrito. Com prosas tão carregadas quanto os próprios objetos das suas descrições, essas páginas pretendiam recompor para os contemporâneos 
e a posteridade a imagem e os significados de cada estrutura, de cada manifestação. Entre a crônica, o exercício poético e o relatório, estes textos eram, como os monumentos efêmeros, também obras de circunstância e documentos de época.

A primeira estrutura que a Relação dos Festejos apresenta é o Templo consagrado a Minerva, patrocinado pelo Senado da Câmara. Constava de doze colunas dóricas, e estava decorado com duas figuras alegóricas, que representavam a Poesia e a História. A Junta de Comércio, por sua parte, encomendara um arco triunfal com colunas da ordem coríntia e estátuas de Minerva e Ceres. As pinturas exibiam o Rei, aclamado como "Libertador do Commercio", em várias figurações: desembarcando no porto, recebendo as chaves da cidade, sendo homenageado, como correspondia, pelas alegorias das Artes e do Comércio. Os rios Tejo e Janeiro estavam representados no centro da estrutura, custodiados pelas Armas e a bandeira do Reino e pela coroareal.

Aqui, como em outras geografias, eram os deuses e heróis da antiguidade grega e latina os escolhidos para presidir os significados dos monumentos levantados para homenagear os monarcas. Neste caso era Minerva, a sábia protetora do comércio e das artes, e Ceres, regente das lavouras, mas podia também ser Mercúrio, Ulisses, Hércules, Marte, Perseu, Apolo, Paris ou Aquiles. Muito invocados ao longo dos séculos XVII e XVIII, estes personagens eram utilizados para qualificar os monarcas através do prisma da história das mitologias (RODRIGUEZ HERNÁNDEZ, p. 272). Mediante os modelos heróicos e as fábulas clássicas se buscava enfatizar os paralelismos entre as biografias dos soberanos e as qualidades patentes no mito, que depois seriam desenvolvidos no programa iconográfico dos monumentos.

A Relação indica que no Terreiro do Paço havia sido erigida uma "altíssima pyramide", e que na Rua Direita havia três quadros, em que a augusta figura do Rei estava acompanhada pelas Armas, por Marte e por Fama. As pinturas estavam ornamentadas com legendas em latim e versos 
alusivos em português, que não se caracterizavam nem pela originalidade nem pela sofisticação:

Pregoa a Fama em seu clarim rotundo JOÃO Primeiro Rei no Novo Mundo, Nos Astros fixa a epoca ditosa,

Que no solo, que banha o grão Janeiro, As santas leis dará ao mundo inteiro.

Extasia-se a Europa vendo erguido

Na Plaga do Brazil o Reino Unido. (SOUZA, p.5)

Outras representações podiam ser vistas na Alfândega, no Arsenal Real da Marinha, no Campo de Santa Ana, nas fachadas das casas patrícias. Ninguém queria deixar passar a ocasião, nem parecer austero na hora de demonstrar sua lealdade. O Comendador Luiz de Souza Dias, os negociantes Joaquim JoséPereira de Faroe Francisco Pereira de Mesquita, o maquinista do Real Teatro Luiz Xavier Pereira, o Desembargador do Paço Luiz José de Carvalho, o Tenente General José d’Oliveira Barboza, o Conselheiro José Antonio de Araujo, o Cirurgião Mor dos Exercitos Theodoro Ferreira de Aguiar eram alguns dos membros da sociedade fluminense que competiam com seus arcos triunfais, seus bustos, suas bandeiras, seus poemas e dísticos. Emalguns casos, o autor indicava quem havia sido o artista encarregado de elaborar as iluminações e pinturas, como Auguste Grandjean de Montignyou Jean-Baptiste Debret, membros da célebre Missão Artística Francesa que havia se instalado na cidade em 1816. "Sumptuosa illuminação", "artificiosa symetria", "optimos versos", "espectaculo encantador" eram algumas das locuções que a Relação multiplicava. Tais demonstrações evidenciavam, segundo o cronista, tanto o triunfo absoluto dos quatro afetos que a celebração tinha avivado na sociedade ("Respeito, Contentamento, Vassalagem, Afabilidade") quanto a consagração da alegria popular: 
O jubilo manifestava-se em toda a gente de todas as condições. He inexplicavel o enthusiasmo, com que o Povo ambicionava a Amabilissima Presença de S. MAGESTADE, e de toda a FAMILIA REAL, formigando para Lhes ocurrer nas diferentes ruas, por onde passavão, e mandando-Lhes os votos mais fieis nos expressivos, e amiudados 'Vivas` que resoavam de toda a parte. (SOUZA, p.14).

Relembrando os artefatos, as respostas que provocaram e os clamores urbanos multiplicados pelas celebrações, essa primeira parte da Relação tenta recriar aquilo que foi uma vez visível e já inexiste, e aspira a recuperar, com vívido discurso, a experiência da contemplação. Ao descrever as pinturas e o tamanho dos arcos, as estátuas, os peristilos e a ordem das colunas, as diversas alegorias dos quatro continentes e as legendas e inscrições, as iluminações e bandeiras nos palacetes que, durante esses dias, haviam transformado o Rio de Janeiro, o cronista incorre numa prática que contava com longa tradição e prestígio nas artes retóricas: a écfrase. A écfrase supõe um trabalho de interpretação da matéria visual, tal como esta perdura na rememoração. Emulação verbal das cores, das sombras e dos relevos, revisão dos ilusionismos e coloridos enganos que os artefatos haviam instalado no espaço urbano, a écfrase manifesta o propósito descritivo e explicativo que, junto com a intenção laudatória, justificam a escrita do opúsculo. Não se trata de postular uma identidade absoluta entre a pintura e o discurso, nem de oferecer uma descrição física mais ou menos "exata" dos objetos (HANSEN, p. 99). Trata-se, antes de tudo, de elaborar um exercício retórico, pautado pelas convenções do gênero epidíctico, o gênero do tempo presente, o mais adequado para multiplicar os encômios dirigidos ao aclamado Rei do novel Reino Unido.

Toda a Relação dos Festejos então pode ser vista como uma oração panegírica. Com suas prosaicas descrições e seus lugares comuns está também intimamente associada comas urgências e limitações do discurso 
jornalístico. Contudo, e embora o texto lembre às vezes uma mera matéria de jornal, deve ser visto como muito mais do que isso, quer dizer, como o que realmente era: um artefato mais, como as pirâmides e os arcos triunfais, criado para propiciar as aclamações. Efêmeros, os artefatos haviam provocado respostas imediatas no público, antes de desaparecer para sempre. Posterior e conclusivo, o texto impresso era ainda capaz de prolongaresses efeitos eesses louvores muito depois deque as festividades houvessem acabado.

Esse caráter encomiástico é ainda mais notório na segunda parte, que reúne os poemas redigidos para exaltar a biografia e as qualidades do Rei. Nesta parte não há comentários nem descrições, apenas aparecem os textos, em breve antologia. Conforme foi dito anteriormente, a coletânea inclui odes, um soneto e um canto épico. Estes poemas estabelecem um contraponto com os outros, menores e mais simples, que apareciam na primeira parte, que geralmente eram transcrições de versos que haviam sido colocados na via pública, nos monumentos e fachadas, durante as festividades. As três odes são igualmente exaltadas, apologéticas e árduas para um leitor contemporâneo, mas cada uma delas conserva, mesmo sem fugir um ápice das rígidas pautas do gênero, sua particularidade. A primeira, seguindo o modelo pindárico, multiplica as estrofes, as antístrofes e os epodos. A composição carece de título, e, das três odes, é a que mais se ocupa da conturbada situação geopolítica da época. Apresenta um mundo atravessado pela destruição e o conflito, para contrastá-lo com o pacífico Reino e o famoso monarca que eram o objeto dos seus cantos:

Do crime entre os baldões, de sangue involta, Geme a Europa infeliz, e o mundo geme;

Plutão as Furias solta;

Enluta-se a Razão, e a Natureza

Adulterada de si mesma treme;

São intriga, e furor pais da revolta; 
Da Discordia fatal a tocha aceza

Faiscas infernaes ao mundo lança

Da ígnea fonte, que borbulha em França. (SOUZA, p. 20)

Se, para o autor, a França (e em menor medida a Espanha) são as magnas responsáveis pela dissolução que ameaça o presente, cabe ao novo reino lusitano oferecer um refúgio contra todos os males e discórdias que assolavam esse mundo:

Septro leve e suave os Lusos rege

No meio da tormenta do Universo,

Do systema perverso

As victimas protege,

Benigno ocorre o Principe Piedozo;

E o bando lastimozo

De infelizes deo vida o seu thezouro:

Filhos do Sena acharão doce gôzo

No Tejo ameno, no espumante Douro. (SOUZA, p. 20)

Como uma verdadeira antístrofe contra as calamidades do tempo, os Lusos e o Reino Unido, "no meio da tormenta do Universo", auguram paz e harmonia, sob o comando do "Gram Monarca" que será capaz, conforme o poeta, de dominar os mares com "lusitanas quinas".

A segunda ode, intitulada "À feliz aclamacção do muito alto e poderoso Rey o Senhor D. João VI", está composta toda em quartetos; não se refere tanto à situação internacional, e prefere focar todos seus ditirambos na figura do monarca, a quem interpela diretamente, como se estivesse de corpopresente, ouvindo. Apesar de que mencionarapidamente o evento mais transcendente da historia europeia desses últimos anos ("Se teu Povo europeu duras algemas/quebrou do Usurpador envergonhado"), a ênfase está aqui dirigida a enumerar todas as virtudes do soberano e a confirmar todas as lealdades dos seus súditos. D. João éo "Pai do seu Povo; em que este Povo/ fidelidade jura", o aclamado por "Grandes, pequenos, 
homens, e mulheres/Pelas ruas, janellas, pela praça"; um soberano que, perante as provas de lealdade e afeição recebidas, dificilmente poderia ser comparado com nenhum outro.

A terceira e última ode, também em quartetos, é a que mais se alonga em enunciar os feitos passados dos lusitanos, e a que dá maior destaque ao Brasil e ao Novo Mundo. Celebra a "faustissima acclamação d El Rey Nosso Senhor" relembrando as antigas estirpes reais e as glórias marítimas eternizadas por Cabral e Vasco da Gama. Evoca a cornucópia da natureza brasileira, definida mediante generosos epítetos como "plaga nova", "plaga majestosa", "pais abundoso", "rica terra". E augura um futuro igualmente glorioso parao Reino, que, num "mundo emdesavença" haverá de ser uma ilha de harmonia, governada por figura equiparável ao imperador romano tantas vezes elogiado pelos historiadores antigos, o "Luzo Tito, que hoje cinge a Diadema":

Que imensa perspectiva de ventura

No dourado por vir se descortina!

A Paz, a Gloria, a Industria, foragidas

De hum mundo em desavença.

Batendo as brancas bemfazejas asas,

Transpõem o fundo Atlanthico, lá pouzão

No abundoso Pais, que largo abração

O Amazonas, e o Prata. (SOUZA, p.33)

A seguir, o "Canto Épico" (que, como vimos, está assinado pelo escriturário e soldado Estanislau Vieira Cardozo) parece ser a mais elaborada, e a mais ambiciosa, destas composições. É também a mais ostensiva em multiplicar os hipérbatos, os cultismos, os chamados às musas e as alusões ao gosto dos entendidos. A hipérbole é figura repetida, como neste terceto, que talvez não seja dos mais hiperbólicos:

E o Brasilico Génio, e o Génio Luso

Progenitor, e Prole germanando,

Hão de invejas cravar ao mundo inteiro. (SOUZA, p. 45) 
Conforme as exigências do gênero, o Rei, suas virtudes e suas sábias políticas são os receptáculosnecessários das maiselaboradas dessas ênfases, como, entre muitas outras, estas que descrevem a passagem da figura real pelas ruas da cidade:

Urge porem Politica Sublime, que Prossigas a Róta. Oh que alvoroço

Do Fluminense Povo ao Teu Ingresso!

Dos grandes Propugnáculos obumbrão.

Bronzi-férreos Trovões, os leves ares.

Innúmeros baixeis as Ondas cruzão.

Ribas, Colinas súbito se apinhão

De gente absorta, que forceja inútil

Por ver Aquelle que na mente goza. (SOUZA, p. 40)

Artifícios como estes eram totalmente previsíveis no contexto da Relação, mas há no "Canto épico" um elemento que, entretanto, chama mais a atenção: o uso das notas de rodapé. Essa conspícua presença das notas serve para traduzir e esclarecer algum circunlóquio que no Canto havia remetido à conjuntura premente. Como quando explicitam as medidas de governo tomadas pelo monarca ou aludem a eventos da política internacional ou aos dramáticos episódios da Revolução Pernambucana que fora sufocada pelas forças monarquistas no ano anterior, as notas tecem o vínculo entre a dicção poética e a história.

Nesse caso, o triunfo contra os sublevados pernambucanos é assim comparado com as grandes vitorias militares dos heróis clássicos: a nota de rodapé oferece o nome completo e o cargo do combatente realista que no poema havia sido invocado mediante algum emblema ou outro recurso. O poeta, enunciando em terceira pessoa -a voz fundante do gênero épico-, articula com seu testemunho os mundos da imaginação e os mundos do acontecimento. Se, através da expressão grandiloquente, ocorre a passagem da dimensão real à dimensão mítica (a passagem que constitui a matéria épica), através das notas se tende outra ponte, desta vez entre a natureza épica e a concretude do real. 
Deste modo, se o episódio histórico, concreto e/ou já mitificado, costuma ser a matéria basilar da épica, estas prosaicas notas de rodapé poderiam ser lidas então como a explicitação mais evidente desse vínculo: uma explicitação periférica, destinada a um hipotético leitor que porventura precisasse de esclarecimentos. Por outra parte, curiosamente, as notas também são utilizadas para tecer reflexões sobre o próprio texto, sobre a conveniência de usar um advérbio ou para reforçar algum traço intertextual com Camões. Como faz Carlos Argentino Daneri em "El Aleph" de Jorge Luis Borges, Vieira Cardozo comenta, critica e elogia sua própria obra, o que para o leitor atual provoca certo efeito paródico que, decerto, o escriturário poeta jamais poderia haver previsto nem desejado.

A breve e efusiva coletânea de poemas alusivos à aclamação real se fecha com um singelo soneto que exalta mais uma vez o "Grande Rey", que agora contemplava os vastos e unidos domínios lusitanos do trono estabelecido na baía de Guanabara. O resto da história, todavia, é por todos conhecida. Contrariando os augúrios e esperanças dos poetas, apenas três anos depois de ser aclamado, o Rei haveria de voltar definitivamente a Portugal. No ano seguinte, o Reino Unido deixaria de existir e o Brasil passaria a ser uma nação independente. Tão efêmeras como os arcos triunfais e as iluminações que haviam decorado a cidade, as loase juras enunciadas pelos leais poetas da Relação dos Festejos haveriam de caducar definitivamente, como se pertencessem a um tempo já remoto e tão arcaico quanto suas próprias metrificações.

\section{Referências bibliográficas}

HANSEN, João Adolfo. Categorias epidíticas da ekphrasis. Revista USP, São Paulo, n 71, p. 85-105, setembro/novembro 2006.

MARAVALL, José Antonio. La cultura del barroco. Barcelona: Ariel, 1983. 
METELO DE SEIXAS, Miguel. As Armas do Reino Unido de Portugal, Brasil e Algarves. Olisipo, II série, n 14, Jan-Jul. 2001, p. 110-127.

RODRIGUEZ HERNÁNDEZ, Dalmacio. Los arcos triunfales en la época de Carlos II: una aproximación desde la retórica. In: Farré Vidal, Judith(ed.)Teatro y poder en la época de Carlos II. Fiestas en torno a reyes y virreyes. Madrid/Frankfurt am Main: Iberoamericana/ Vervuert, 2007, p. 267-286.

SOUZA, Bernardo Avellino Ferreira e. Relação dos Festejos que a feliz aclamação do muito alto, muito poderoso, e fidelíssimo Senhor D. João VI. Rio de Janeiro: Typographia Real, 1818. 